\title{
Severe reflux esophagitis after total gastrectomy successfully treated by transposition of the jejunojejunal anastomosis: a report of two cases
}

\author{
Noriyuki Nishiwaki ${ }^{*}$ (D), Shinji Hato ${ }^{1}$, Tetsuya Kagawa ${ }^{2}$, Tomokazu Kakishita ${ }^{1}$ and Isao Nozaki ${ }^{3}$
}

\begin{abstract}
Background: Reflux esophagitis after total gastrectomy is often difficult to treat. In this report, we describe two cases of reflux esophagitis that were refractory to medical therapy and successfully treated by transposition of the jejunojejunal anastomosis.

Case presentation: Case 1: A 66-year-old man underwent total gastrectomy and cholecystectomy for gastric cancer, and Roux-en-Y (RY) reconstruction was performed. The pathological diagnosis was T4aN3aM0 stage IIIC. Five months later, esophagogastroduodenoscopy identified reflux esophagitis. Although he was treated with various oral medications and was hospitalized six times, he lost $19 \mathrm{~kg}$ of weight. Finally, the patient was reoperated 3 years postoperatively. Intraoperative findings showed that there was no evidence of recurrence or severe adhesions that could have caused obstruction, and the anastomotic distance between the esophagojejunostomy and the jejunojejunostomy was approximately $40 \mathrm{~cm}$. The jejunojejunostomy was re-anastomosed to increase the distance to $100 \mathrm{~cm}$. Two years and 6 months after the reoperation, there was no recurrence of reflux esophagitis, and the patient's weight increased by $14 \mathrm{~kg}$.

Case 2: A 68-year-old woman underwent total gastrectomy and cholecystectomy for gastric cancer, and RY reconstruction was performed. The pathological diagnosis was T4aNOMO stage IIB. Similar to Case 1, the patient was diagnosed with reflux esophagitis 5 months later. She lost $23 \mathrm{~kg}$ of weight and was reoperated at 6 months postoperatively. Intraoperative findings showed that there was no evidence of recurrence or severe adhesions, and transposition of the jejunojejunostomy was performed to increase the distance between anastomoses from 40 to $100 \mathrm{~cm}$. Two years and 8 months after the reoperation, there was no recurrence of reflux esophagitis, and her weight increased by $15 \mathrm{~kg}$.
\end{abstract}

Conclusions: Transposition of the jejunojejunostomy was an effective treatment for medication-resistant severe reflux esophagitis after total gastrectomy.

Keywords: Total gastrectomy, Reflux esophagitis, Jejunojejunostomy

*Correspondence: nishiwaki.noriyuki.yx@mail.hosp.go.jp

1 Department of Surgery, National Hospital Organization, Shikoku Cancer Center, 160, Ko, Minamiumemoto-machi, Matsuyama-shi, Ehime-Ken 791-0280, Japan

Full list of author information is available at the end of the article

\section{Background}

Reflux esophagitis is a complication that can occur after total gastrectomy [1]. Although Roux-en-Y (RY) reconstruction has significantly decreased the incidence of this complication, when it does occur, it is often difficult to treat [2-4]. In this report, we describe two cases of reflux 
esophagitis that were refractory to medical therapy and successfully treated by transposition of the jejunojejunal anastomosis.

\section{Case presentation}

Case 1: A 66-year-old man underwent open total gastrectomy and cholecystectomy for gastric cancer, and RY reconstruction was performed. The pathological diagnosis was T4aN3aM0 Stage IIIC (Japanese classification of gastric cancer $15^{\text {th }}$ ), and he was a candidate for adjuvant chemotherapy. However, he was unable to maintain this therapy due to severe nausea. Five months later, symptoms of heartburn and nausea persisted despite the absence of chemotherapy, and esophagogastroduodenoscopy identified grade C esophagitis (Los Angeles classification). The radiographic contrast study did not show any bowel obstruction. Although he was treated with various oral medications and was hospitalized six times, central venous hyperalimentation and enteral feeding were attempted, which were ineffective. The patient had lost $19 \mathrm{~kg}$ of weight since the initial surgery. Finally, he underwent reoperation after confirming no recurrence at 3 years postoperatively. Intraoperative findings showed no evidence of recurrence or severe adhesions in the abdominal cavity. The gaps between the mesentery of jejunojejunostomy, Petersen's defect, and the transverse colonic mesentery through the elevated jejunum, which were closed at the time of the initial surgery, were also closed. There were no findings of internal hernia or intestinal adhesions that could have caused intestinal obstruction. The anastomotic distance between the esophagojejunostomy and jejunojejunostomy was approximately $40 \mathrm{~cm}$ (Fig. 1a). After the jejunojejunostomy was dissected and closed, it was re-anastomosed to create a distance of $100 \mathrm{~cm}$ (Fig. 1b). The patient was discharged on the 20th postoperative day without any postoperative complications. The clinical course, body weight, albumin, Onodera's prognostic nutrition index (PNI),

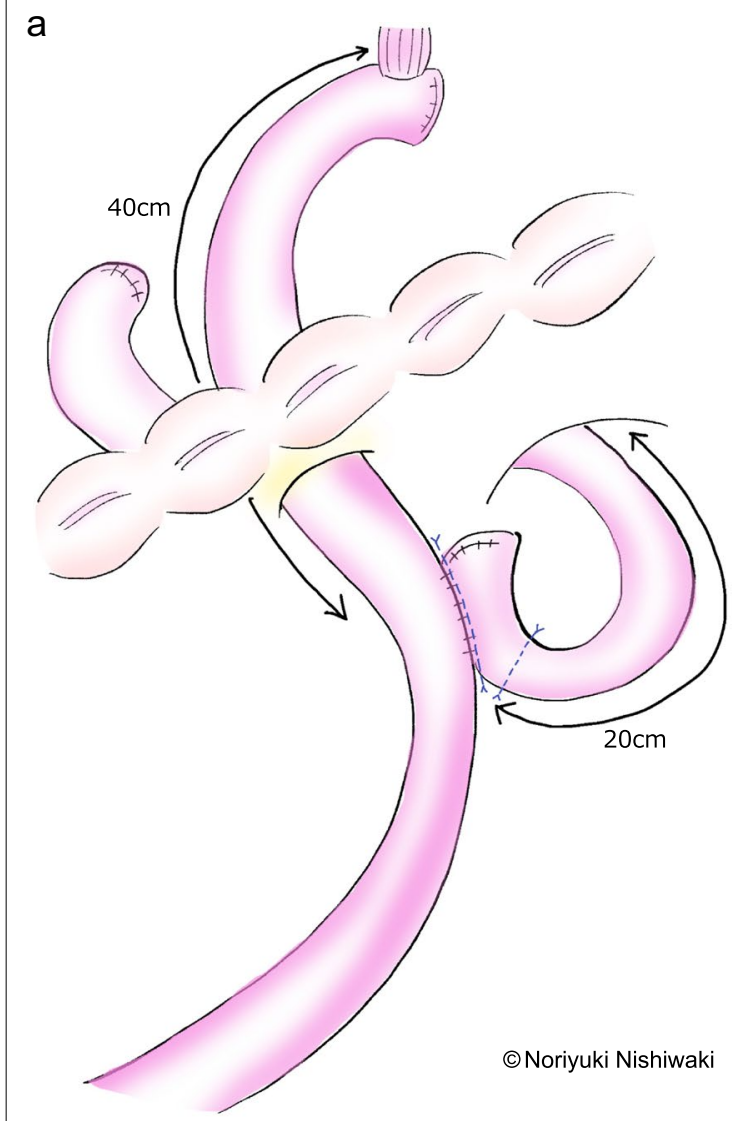

Before re-anastomosis b

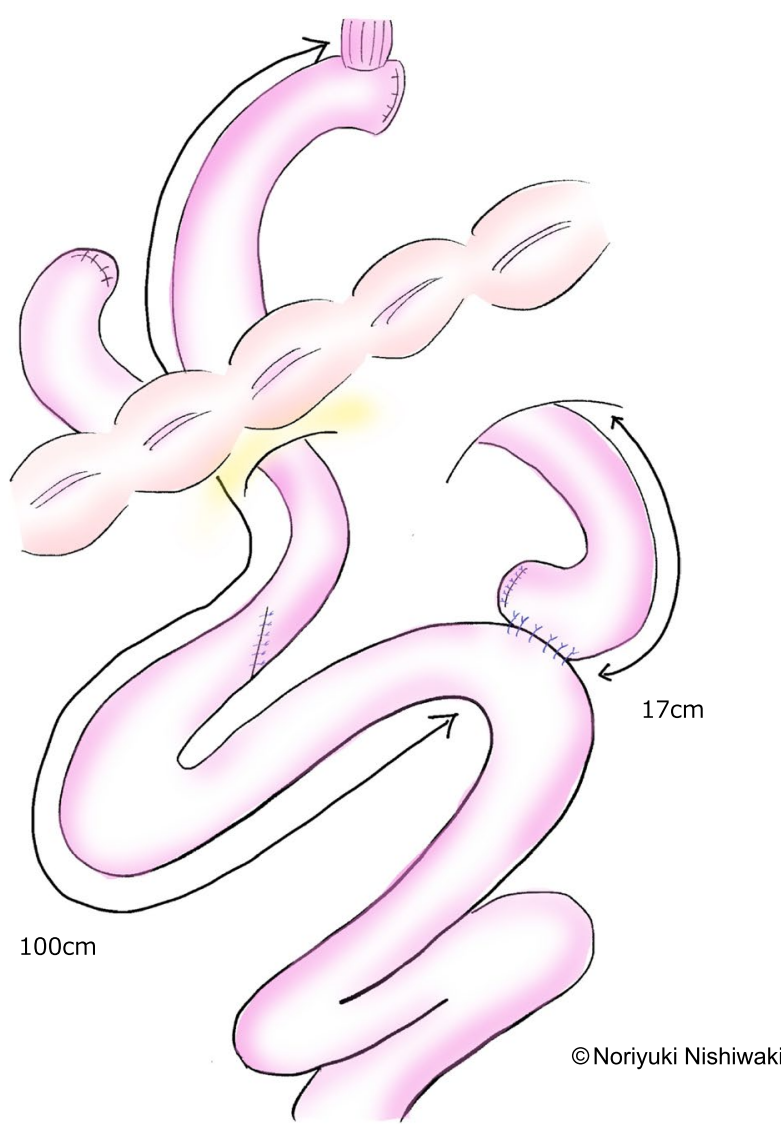

After re-anastomosis

Fig. 1 Schemes of intraoperative findings. a The anastomotic distance between the esophagojejunostomy and the jejunojejunostomy was about $40 \mathrm{~cm}$. The cutting lines of the jejunum were shown in blue lines. $\mathbf{b}$ After the jejunojejunostomy was dissected and closed, it was re-anastomosed to make anastomotic distance $100 \mathrm{~cm}$ 
and treatment details are shown in Fig. 2. Two years and 6 months after the reoperation, there was no recurrence of reflux esophagitis or related symptoms without any medications, and the patient's weight increased from 36 to $50 \mathrm{~kg}$, albumin increased from 3.1 to $4.4 \mathrm{mg} / \mathrm{dL}$, and PNI increased from 37.8 to 53.8 (Fig. 2).

Case 2: A 68-year-old woman underwent open total gastrectomy and cholecystectomy for gastric cancer, and RY reconstruction was performed. She was eligible for adjuvant chemotherapy due to stage IIB (T4aNOM0) pathology, but did not wish to receive it due to the experience of severe side effects from previous postoperative chemotherapy for uterine cancer. Five months later, esophagogastroduodenoscopy identified grade $\mathrm{C}$ esophagitis (Los Angeles classification). The radiographic contrast study did not show any bowel obstruction. She was also refractory to medical treatment and had lost $23 \mathrm{~kg}$ of weight since the initial surgery. Finally, the patient was reoperated at 6 months postoperatively.
Similar to Case 1, there was no recurrence or severe adhesions, and the jejunojejunostomy was re-anastomosed to increase the anastomotic distance from 40 to $100 \mathrm{~cm}$. The patient was discharged on the 25 th postoperative day without any postoperative complications. Two years and 8 months after the reoperation, there was no reoccurrence of reflux esophagitis without any medications, her weight increased from 44 to $59 \mathrm{~kg}$, albumin increased from 3.3 to $3.7 \mathrm{mg} / \mathrm{dL}$, and PNI increased from 41.9 to 46.3 (Fig. 3).

\section{Discussion}

The cause of reflux esophagitis after total gastrectomy is flow of duodenal fluid, including bile and pancreatic juice $[5,6]$, into the esophagus. In severe cases, it causes not only heartburn and weight loss, but also Barrett's adenocarcinoma in the long term [7]. The role of the different components of this refluxate in the pathogenesis of reflux esophagitis after total gastrectomy is only partially

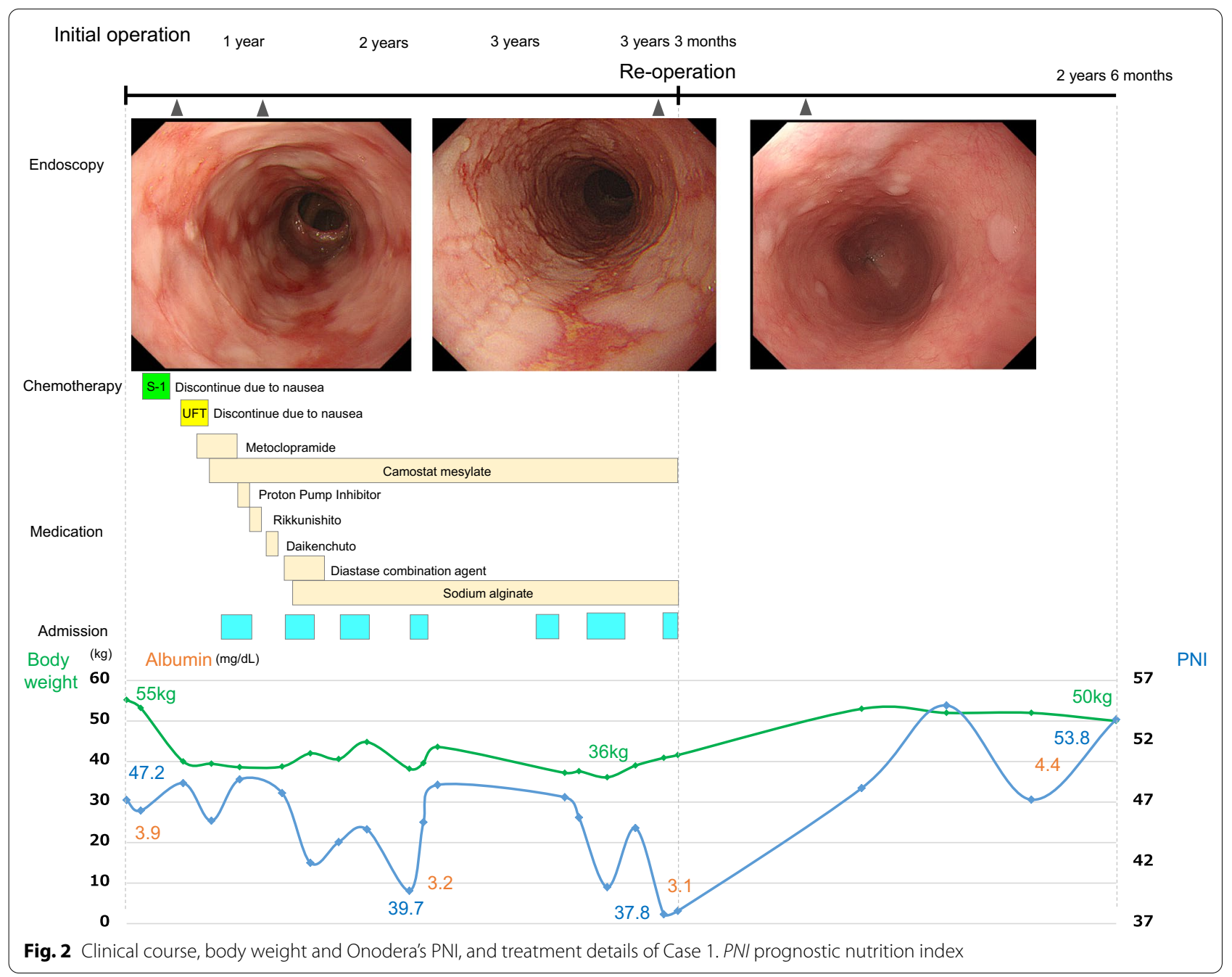




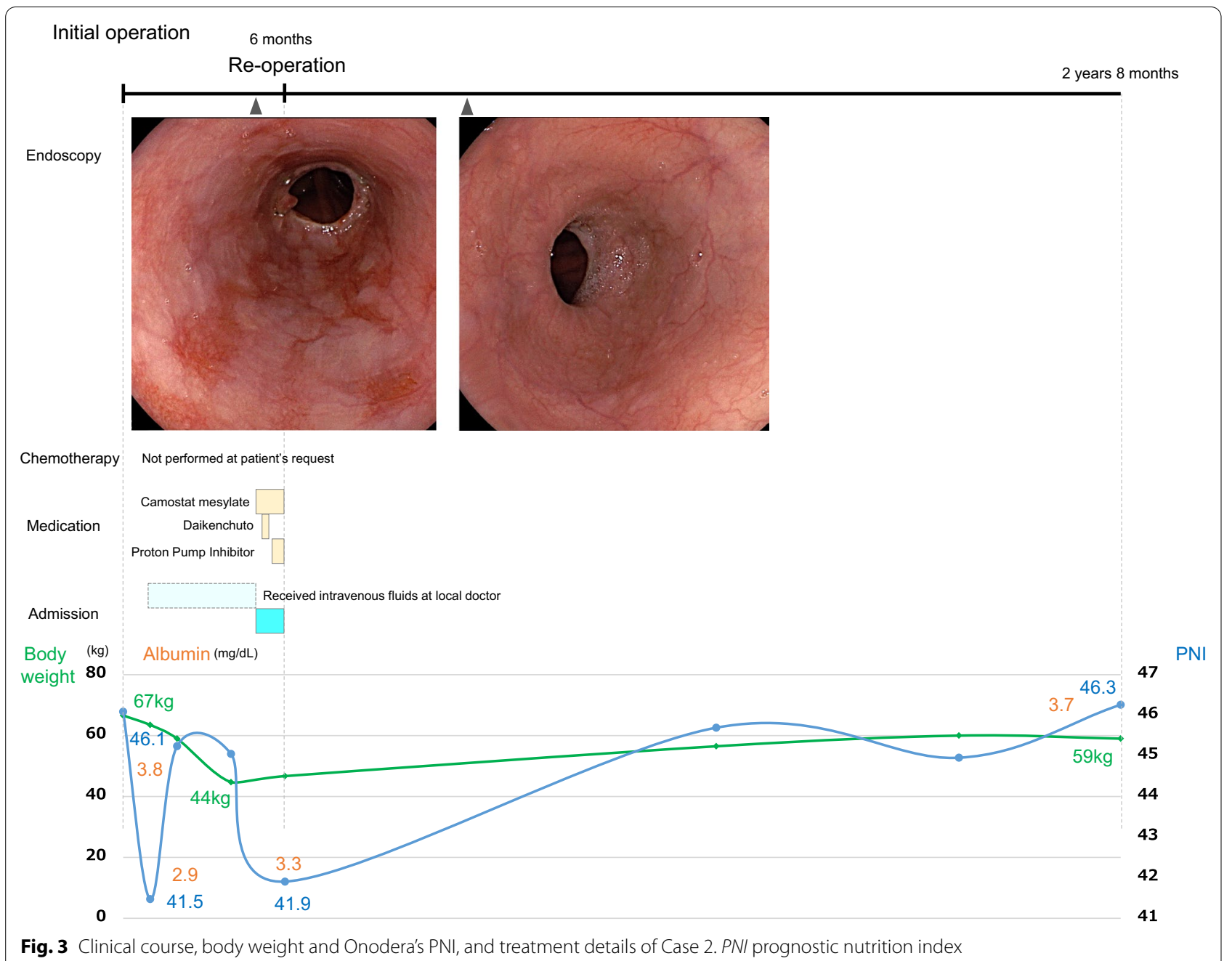

known. Some studies in animals have shown that trypsin, deconjugated bile salts, and lysolecithin are more damaging to the esophagus in the absence of gastric acid $[8,9]$. In recent years, although there have been some reports on the use of $\mathrm{pH}$ and bilirubin monitors to aid in the diagnosis and understanding of pathogenesis [1012], present cases did not receive those examinations. Although the main treatment is medication to inhibit digestive enzymes, surgery can be performed if there is resistance.

In this study, we evaluated the status of the two patients before and after reoperation from two perspectives: body weight and nutritional indicators. Body weight loss significantly influences a patient's quality of life after gastrectomy [13]. In the present two cases, weight loss progressed due to esophagitis symptoms, with a maximum of $19 \mathrm{~kg}$ in Case 1 and $23 \mathrm{~kg}$ in Case 2, which was a decrease from the preoperative weight, but the weight increased after reoperation.
Onodera's PNI reflects nutritional status and is calculated as follows: $10 \times$ serum albumin (g/ $\mathrm{dL})+0.005 \times$ lymphocyte count $\left(\right.$ per $\left.\mathrm{mm}^{3}\right)$ [14]. Preoperative malnutrition is associated with poor prognosis after gastrectomy, and PNI has been reported to be associated with poor prognosis in the low PNI group when the cutoff was set at 44.7-47.8 [14-16]. Although PNI decreased to a minimum of 37.8 in Case 1 and 41.5 in Case 2, it increased to over 46 after reoperation, indicating that reoperation also improved nutritional status.

There were six cases of reoperation for reflux esophagitis after total gastrectomy and RY reconstruction reported from Japan and overseas (Table 1) [11, 12, 17]. In all cases, the surgery was performed safely with a relatively short operation time and a small amount of blood loss. In both our cases, although there were some adhesions in the upper abdomen, they did not affect the reanastomosis, and the patients were discharged without any complications. The time between the initial surgery 
Table 1 Cases of reoperation for reflux esophagitis after total gastrectomy and Roux-en-Y reconstruction

\begin{tabular}{|c|c|c|c|c|c|c|c|c|}
\hline $\begin{array}{l}\text { Reports } \\
\text { (year) }\end{array}$ & Age/sex & Symptom & $\begin{array}{l}\text { Endoscopic } \\
\text { findings** }\end{array}$ & $\begin{array}{l}\text { Time } \\
\text { between } \\
\text { initial } \\
\text { surgery and } \\
\text { reoperation } \\
\text { (months) }\end{array}$ & $\begin{array}{l}\text { Preoperative } \\
\text { distance between } \\
\text { esophagojejunostomy } \\
\text { and jejunojejunostomy } \\
\text { (cm) }\end{array}$ & $\begin{array}{l}\text { Postoperative } \\
\text { distance between } \\
\text { esophagojejunostomy } \\
\text { and jejunojejunostomy } \\
\text { (cm) }\end{array}$ & $\begin{array}{l}\text { Operation } \\
\text { time } \\
\text { (minutes) }\end{array}$ & $\begin{array}{l}\text { Blood loss } \\
\text { (ml) }\end{array}$ \\
\hline $\begin{array}{l}\text { Collard et al. } \\
\text { (2002) [17] }\end{array}$ & NA & Heartburn & NA & NA & 60 & 110 & NA & NA \\
\hline $\begin{array}{l}\text { Collard et al. } \\
\text { (2002) [17] }\end{array}$ & NA & Heartburn & NA & NA & 60 & 110 & NA & NA \\
\hline $\begin{array}{l}\text { Takahashi } \\
\text { et al. (2008) } \\
{[12]}\end{array}$ & $72 / \mathrm{M}$ & $\begin{array}{l}\text { Heartburn, } \\
\text { body } \\
\text { weight loss }\end{array}$ & Grade D & 5 & 30 & 130 & 155 & 50 \\
\hline $\begin{array}{l}\text { Miyamura } \\
\text { et al. (2016) } \\
{[11]}\end{array}$ & $57 / \mathrm{M}$ & $\begin{array}{l}\text { Heartburn, } \\
\text { body } \\
\text { weight loss }\end{array}$ & Grade D & 18 & 30 & 90 & 115 & 30 \\
\hline Case 1 & $68 / M$ & $\begin{array}{l}\text { Anorexia, } \\
\text { body } \\
\text { weight loss }\end{array}$ & Grade C & 39 & 40 & 100 & 110 & 10 \\
\hline Case 2 & $66 / F$ & $\begin{array}{l}\text { Anorexia, } \\
\text { body } \\
\text { weight loss }\end{array}$ & Grade C & 6 & 40 & 100 & 163 & 20 \\
\hline
\end{tabular}

$M$ male, $F$ female, *Los Angeles classification, NA not applicable

and reoperation varied between the cases. The patient in Case 1 took as long as 39 months, while the second patient was reoperated within a shorter period of 6 months. In Case 1, the pathological diagnosis was stage IIIC, indicating a high risk of recurrence, and since the possibility of passage obstruction due to recurrence could not be ruled out, the decision was made to perform reoperation after 3 years of recurrence-free confirmation. For the second case, based on the positive experience of the first, the decision to reoperate was made at a relatively early stage when the patient was resistant to medical treatment. Overall, the rapid improvement in symptoms and lack of recurrence of esophagitis after re-anastomosis suggest that transposition of jejunojejunostomy is effective, and surgical treatment may be considered at a relatively early stage for patients who are refractory to medical therapy.

There are three possible causes of duodenal fluid reflux after total gastrectomy, excluding substrate occlusion mechanisms, such as recurrence or severe adhesions. The first is a reconstructive method. The Billroth II method, in which the duodenal fluid passes through the anastomosis, has been reported to cause esophagitis in 50-60\% of cases, whereas the RY method has been reported to have an incidence of $10-30 \%$ [18]. Next, the shorter the anastomotic distance, the more likely reflux esophagitis occurs, and the frequency decreases when the anastomotic distance is $>40 \mathrm{~cm}$ [19]. However, the frequency of Roux stasis increases when the anastomotic distance exceeds $40 \mathrm{~cm}$ [20], and thus the appropriate anastomotic distance remains a matter of debate. Takahashi and Miyamura reported that the anastomotic distance was as short as $30 \mathrm{~cm}$, and it was considered that the short distance was the cause of reflux esophagitis $[11,12]$. However, our two cases revealed that reflux occurred even at a distance of $40 \mathrm{~cm}$. Therefore, it is important to keep in mind that some patients may experience reflux even when the anastomotic distance is sufficient. At the time of reoperation, we set the anastomotic distance of $100 \mathrm{~cm}$ based on the report of Collard et al. [17], and the patients have progressed without malabsorption. According to the six reported cases, it seems that an anastomotic distance of $100 \mathrm{~cm}$ for re-anastomosis is a good guideline. Finally, the decrease in lower esophageal pressure due to the dissection of the lower esophagus and the negative pressure on the anastomosis due to the esophageal jejunal anastomosis being located in the thoracic cavity may also be factors in reflux [10]. In both cases, the esophageal dissection length was more than $2 \mathrm{~cm}$, and the anastomosis was in the thoracic cavity, which could have contributed to reflux. Thus, in cases of total gastrectomy requiring lower esophagectomy, it may be necessary to increase the distance between the anastomoses.

\section{Conclusions}

We present two cases of reflux esophagitis that were successfully treated by transposition of the jejunojejunal anastomosis. Transposition of the jejunojejunostomy was an effective treatment in both cases for medicationresistant severe reflux esophagitis after total gastrectomy. 


\section{Abbreviations}

PNI: Prognostic nutrition index; RY: Roux-en-Y.

\section{Acknowledgements}

We thank Editage (www.editage.com) for English language editing.

\section{Authors' contributions}

NN drafted the manuscript and provided the original images. SH, TK, and IN performed the surgeries. SH and TK reviewed and revised the manuscript. All authors read and approved the final manuscript.

\section{Funding}

No funding was received for this study.

\section{Availability of data and materials}

The data supporting the conclusions are included in the article.

\section{Declarations}

Ethics approval and consent to participate

Not applicable.

\section{Consent for publication}

Written informed consent for publication of this case was obtained from the patients.

\section{Competing interests}

The authors declare that they have no competing interests.

\section{Author details}

'Department of Surgery, National Hospital Organization, Shikoku Cancer Center, 160, Ko, Minamiumemoto-machi, Matsuyama-shi, Ehime-Ken 791-0280, Japan. ${ }^{2}$ Department of Gastroenterological Surgery, Fukuyama City Hospital, 5-23-1, Zao-cho, Fukuyama City, Hiroshima Prefecture 721-8511, Japan. ${ }^{3}$ Department of Surgery, National Hospital Organization Okayama Medical Center, 1711-1 Tamasu, Kita-ku, Okayama City, Okayama 701-1192, Japan.

Received: 11 November 2021 Accepted: 9 December 2021

Published online: 20 December 2021

\section{References}

1. Matei D, Dadu R, Prundus R, Danci I, Ciobanu L, Mocan T, et al. Alkaline reflux esophagitis in patients with total gastrectomy and Roux en $Y$ esojejunostomy. J Gastrointestin Liver Dis. 2010;19:247-52.

2. Hubens $A$, van Hee R, van Vooren W, Peeters R. Reconstruction of the digestive tract after total gastrectomy. Hepatogastroenterology. 1989;36:18-22.

3. Salo JA, Kivilaakso E. Failure of long limb Roux-en-Y reconstruction to prevent alkaline reflux esophagitis after total gastrectomy. Endoscopy. 1990;22:65-7.

4. Schrock TR, Way LW. Total gastrectomy. Am J Surg. 1978;135:348-55.

5. Yumiba T, Kawahara H, Nishikawa K, Inoue Y, Ito T, Matsuda H. Impact of esophageal bile exposure on the genesis of reflux esophagitis in the absence of gastric acid after total gastrectomy. Am J Gastroenterol. 2002:97:1647-52.

6. Endo M, Kono T, Yamasaki S. Pathophysiology and treatment after gastrectomy recent advances. Reflux esophagitis and esophageal achalasia. Gastroenterol Seminar. 1989;35:109-20.

7. Aoyagi K, Kohfuji K, Yano S, Murakami N, Hori H, Terasaki Y, et al. Histopathological findings of the lower esophagus after total gastrectomy in rat. Kurume Med J. 1999:46:167-70.

8. Kamiyasu K, Awata H, Inoshiri S, Doi A, Omawari N, Okegawa T, et al. Effects of FOY-305 on post-operative reflux esophagitis in rats. (I) Effects of FOY-305 on reflux esophagitis after total gastrectomy in rats. Folia Pharmacologica Japónica. 1991;97:241-9.
9. Kamiyasu K, Inoshiri S, Doi A, Omawari N, Okegawa T, Kawasaki A, et al. Effects of FOY-305 on post-operative reflux esophagitis in rats. (II) Analysis of mechanism in the pathogenesis of reflux esophagitis after total gastrectomy in rats. Nihon Yakurigaku Zassi. 1991;97:251-7.

10. Nakamura T, Namatame K. Reflux esophagitis after total gastrectomy with manometric study and 24-hour pH monitoring influence in lower esophageal high-pressure zone. Jpn Soc Gastroenterol Surg. 1993;26(7):1913-20

11. Miyamura K, Kurumiya Y, Mizuno K, Sekoguchi E, Kobayashi S, Yuasa N A case of successful reoperation for severe reflux esophagitis after total gastrectomy. J Jpn Surg Assoc. 2016;77(9):2201-5.

12. Takahashi T, Miyata K, Yuasa N, Takeuchi E, Goto Y, Miyake H, et al. A case of severe reflux esophagitis after total gastrectomy cured by reoperation. Jpn Soc Gastroenterol Surg. 2018;41(4):388-92.

13. Terashima M, Tanabe K, Yoshida M, Kawahira H, Inada T, Okabe H, et al. Postgastrectomy Syndrome Assessment Scale (PGSAS)-45 and changes in body weight are useful tools for evaluation of reconstruction methods following distal gastrectomy. Ann Surg Oncol. 2014;21(Suppl 3):S370-8.

14. Kanda M, Mizuno A, Tanaka C, Kobayashi D, Fujiwara M, Iwata N, et al. Nutritional predictors for postoperative short-term and long-term outcomes of patients with gastric cancer. Med (Baltim). 2016;95:e3781.

15. Sakurai K, Ohira M, Tamura T, Toyokawa T, Amano R, Kubo N, et al. Predictive potential of preoperative nutritional status in long-term outcome projections for patients with gastric cancer. Ann Surg Oncol. 2016;23:525-33.

16. Watanabe $M$, Iwatsuki $M$, Iwagami $S$, Ishimoto T, Baba Y, Baba H. Prognostic nutritional index predicts outcomes of gastrectomy in the elderly. World J Surg. 2012;36:1632-9.

17. Collard JM, Romagnoli R. Roux-en-Y jejunal loop and bile reflux. Am J Surg. 2000;179:298-303.

18. Taniguchi K, Sasagawa T, Takeuchi S, Yamada T, Suzuki H, Kitamura Y, et al. A case of severe reflux esophagitis after total gastrectomy reconstruction in Billroth-II resolved by a simple Reoparation. The J Jpn Coll Surg (in Japanese). 2011;36(4):937-41.

19. Iwanaga T. Reflux esophagitis. Adult Dis (in Japanese). 1972;12:35-43.

20. Gustavsson S, Ilstrup DM, Morrison P, Kelly KA. Roux-Y stasis syndrome after gastrectomy. Am J Surg. 1988;155:490-4.

\section{Publisher's Note}

Springer Nature remains neutral with regard to jurisdictional claims in published maps and institutional affiliations.

\section{Submit your manuscript to a SpringerOpen ${ }^{\circ}$ journal and benefit from:}

- Convenient online submission

- Rigorous peer review

- Open access: articles freely available online

- High visibility within the field

- Retaining the copyright to your article

Submit your next manuscript at $\gg$ springeropen.com 